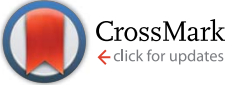

Cite this: RSC Adv., 2017, 7, 15309

\title{
Nanosizing Pd on 3D porous carbon frameworks as effective catalysts for selective phenylacetylene hydrogenation $\uparrow$
}

\author{
Weizhen Yu, ${ }^{a}$ Hongshuai Hou, ${ }^{b}$ Zhiling Xin, ${ }^{a}$ Shuo Niu, ${ }^{a}$ Yanan Xie, ${ }^{a}$ Xiaobo Ji*b \\ and Lidong Shao*a
}

In this work, palladium nanoparticles supported on 3D porous carbon frameworks (Pd/PCFs) were used in the selective hydrogenation of phenylacetylene. Catalytic tests conducted in a continuous-flow reactor coupled with theoretical calculations, HPLC and characterization methods helped to elucidate the structural origins of the observed selectivity patterns. A $62 \%$ selectivity towards styrene with a $93 \%$ conversion was observed in the hydrogenation of phenylacetylene at $20{ }^{\circ} \mathrm{C}$ and 3 bar for a hydrogen flow rate of $12 \mathrm{~mL} \mathrm{~min}{ }^{-1}$ and a reaction

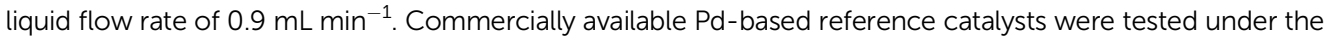
same conditions in phenylacetylene hydrogenation, and the performance of $3 \mathrm{wt} \% \mathrm{Pd} / \mathrm{PCF}$ s was substantiated by studying the geometrical structure of PCFs and the stability of supported Pd nanoparticles under reaction conditions.

Received 4th January 2017

Accepted 2nd March 2017

DOI: $10.1039 / \mathrm{c} 7 \mathrm{ra00123a}$

rsc.li/rsc-advances

\section{Introduction}

The selective hydrogenation of carbon-carbon triple bonds to double bonds is widely used in commodity chemical production, as well as for the synthesis of fine and specialty chemicals. ${ }^{1,2}$ In styrene polymerization, phenylacetylene is an unwanted feedstock that can deactivate catalysts. ${ }^{3-5}$ Hence, phenylacetylene hydrogenation is often used as a model system for evaluating alkyne hydrogenation catalysts, being of both industrial and scientific interest. However, finding new approaches to the synthesis of highly efficient and selective hydrogenation catalysts is still challenging. ${ }^{6}$

Numerous heterogeneous metal catalysts exhibit high activity in the hydrogenation of carbon-carbon double and triple bonds. Noble transition metals such as $\mathrm{Pd}, \mathrm{Pt}, \mathrm{Au}, \mathrm{Ru}$, and $\mathrm{Rh}$ have been used as catalysts for phenylacetylene hydrogenation. ${ }^{7-11}$ Among them, Pd loaded on different kinds of supports, such as silica, carbon, and alumina, has been reported to give relatively high phenylacetylene conversion in the range of $50-60 \%$ under mild conditions at temperatures of $298-353 \mathrm{~K}^{.12}$ Besides the active species, the supporting material is also a factor of great importance, since its interaction with the active species may greatly

${ }^{a}$ Shanghai Key Laboratory of Materials Protection and Advanced Materials in Electric Power, Shanghai University of Electric Power, 2103 Pingliang Road, Shanghai 200090, China.E-mail: lidong.shao@shiep.edu.cn

${ }^{b}$ College of Chemistry and Chemical Engineering, Central South University, Changsha 410083, China.E-mail: xji@csu.edu.cn

$\dagger$ Electronic supplementary information (ESI) available: Details of the catalysts preparation, catalysts characterization and catalytic tests. See DOI: 10.1039/c7ra00123a influence the properties of the resulting catalysts. ${ }^{13,14}$ Lots of novel nanostructured carbon-based materials with unparalleled unique physical and chemical properties have been discovered (e.g., carbon nanospheres, carbon nanofibers, carbon nanotubes, carbon nanosheets, graphene and fullerene) and they have played important roles in catalysis. ${ }^{15,16}$ Among the various supporting carbon materials, porous carbon materials with hierarchical pore structure, large pore volume, tuneable surface chemistry, good electrical conductivity, facile mass transport property and excellent chemical stability are viewed as promising materials for efficient catalysis. ${ }^{17,18}$

Nowadays, the development of low-cost, scalable, economically attractive and sustainable carbon materials based on renewable and highly abundant resources is extremely important. ${ }^{19}$ Herein, a feasible, simplified and productive synthesis procedure to produce 3D porous carbon frameworks (PCFs) with porous structure and morphology by one-step $\mathrm{NaOH}$-assisted treatment of acetone is proposed here (Fig. 1). Sodium hydroxide $(8 \mathrm{~g})$ was mixed with acetone $(40 \mathrm{~mL})$ under stirring for $1 \mathrm{~h}$. After $120 \mathrm{~h}$, the colour of the mixture changed to dark brown, and the liquid acetone was transformed into solid products. Subsequently, the solid products without washing and purification can be transformed into PCFs through calcining at $600{ }^{\circ} \mathrm{C}$ under $\mathrm{He}$ atmosphere. A possible $\mathrm{NaOH}$-assisted mechanism for the formation of PCFs from acetone was proposed in our previous research. ${ }^{20}$ Moreover, the produced PCFs were successfully applied as supports for Pd-based catalysts in selective phenylacetylene hydrogenation under low temperatures for the first time, exhibiting improved catalytic performance with enhanced stability. 


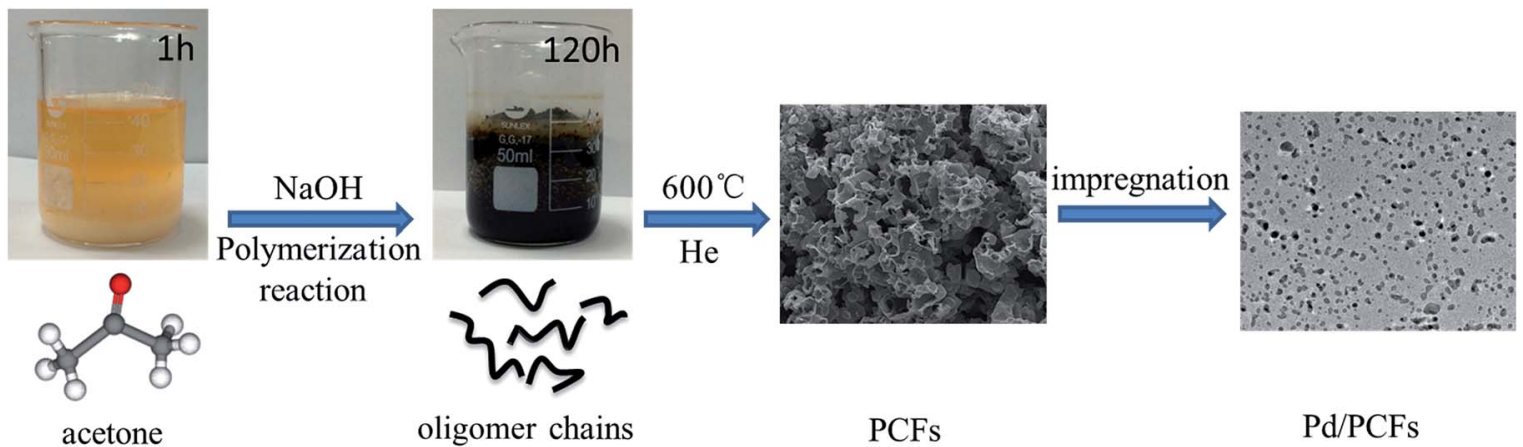

Fig. 1 Schematic diagram depicting the preparation of PCFs and Pd/PCFs.

\section{Results and discussion}

In the present work, palladium nanoparticles supported on porous carbon frameworks (Pd/PCFs) were prepared by impregnation. The actual loadings of the catalysts were $3.051 \mathrm{wt} \%$, as measured by inductively coupled plasma optical emission spectrometer (ICP-OES). Commercially available catalysts featuring palladium on charcoal ( $3 \mathrm{wt} \% \mathrm{Pd} / \mathrm{C})$ and the conventional Lindlar catalyst with a $5 \mathrm{wt} \%$ Pd loading were tested for comparison. Structural and surface analyses were conducted for both the fresh and used catalysts to evaluate their catalytic properties in phenylacetylene hydrogenation and study the supporting effect of PCFs.

The morphology and microstructure of the obtained PCFs were characterized by scanning electron microscopy (SEM), as shown in Fig. 2(a), which displays the shape of the shaggy and porous carbon frameworks composed of interconnected and distorted nanosheets. The as-prepared PCFs exhibit coral-like morphology with numerous micron-sized and nanoscale pores. Evident micron-sized holes are spread around the surfaces and the interior of the carbon frameworks. The porous structure of PCFs was further confirmed by TEM measurements. As shown in

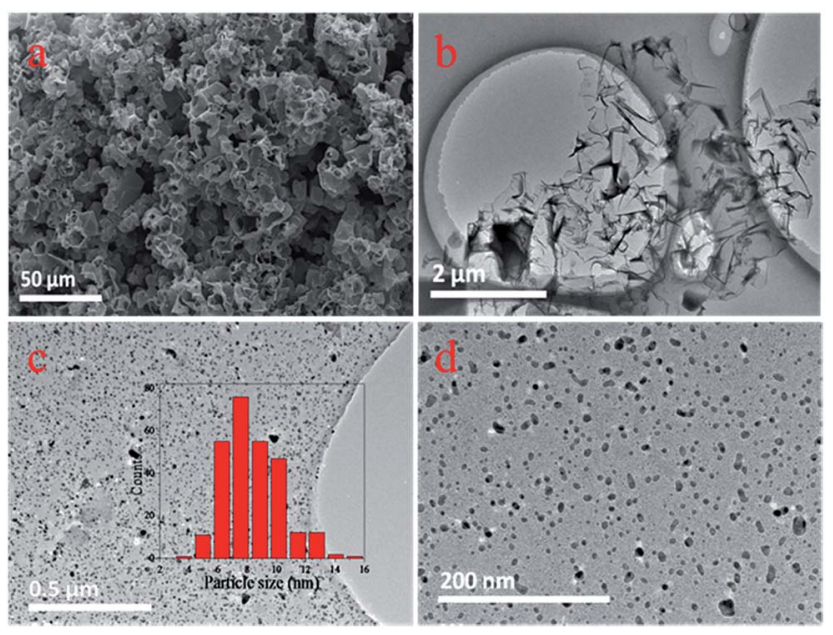

Fig. 2 (a) SEM images of fresh PCFs. (b) TEM images of fresh PCFs. (c and d) TEM images of fresh Pd/PCFs catalysts. The inset in (c) shows the size distribution of palladium nanoparticles.
Fig. 2(b), PCFs feature a three-dimensional interconnected pore system and exhibit an irregular wrinkled structure with curved carbon nanosheets. TEM images of palladium nanoparticles dispersed on the fresh Pd/PCFs catalysts are shown in Fig. 2(c) and (d), showing well-distributed palladium nanoparticles around 3-16 nm uniformly supported on the PCFs.

The specific surface area and pore size distribution of the PCFs were quantified by nitrogen adsorption/desorption studies. As seen in Fig. $\mathrm{S} 1, \uparrow$ the isotherms for the PCFs are of type II with associated $\mathrm{H} 3$ type hysteresis loop, reflecting the macroporous and/or large-mesoporous nature, although micropores are also present. ${ }^{21}$ The BET specific surface areas are estimated to be $258.8 \mathrm{~m}^{2} \mathrm{~g}^{-1}$ for the PCFs prepared at $600{ }^{\circ} \mathrm{C}$. Furthermore, the PCFs exhibited a rather broad pore size range from 5 to $130 \mathrm{~nm}$ (inset), suggesting the formation of a disordered coral-like mesoporous structure, which is consistent with results from SEM measurements.

Catalytic tests were performed in a continuous-flow reactor (ThalesNano $\mathrm{H}$-Cube Pro ${ }^{\mathrm{TM}}$ ) that could be efficiently operated at steady state, offering several advantages for industrial implementation. $^{22}$ The optimum conditions of selective phenylacetylene hydrogenation for Pd/PCFs catalysts were studied by orthogonal experiments (Table $\mathrm{S} 1 \dagger$ ) at various temperatures $\left(20-35{ }^{\circ} \mathrm{C}\right)$, pressures (0-10 bar), and liquid flow rates (0.3-0.9 $\mathrm{mL} \mathrm{min}^{-1}$ ) and $\mathrm{H}_{2}$ flow rates $\left(3-60 \mathrm{~mL} \mathrm{~min}^{-1}\right.$ ); and the effect of temperature, pressure, $\mathrm{H}_{2}$ flow rate and reaction liquid flow rate on the conversion of phenylacetylene and selectivity to styrene can be seen in Fig. $\mathrm{S} 2$ and $\mathrm{S} 3 \uparrow$ respectively. The conversion of phenylacetylene and the selectivity of styrene formation at the optimum conditions $\left(T=20^{\circ} \mathrm{C}, P=3 \mathrm{bar}, \mathrm{H}_{2}\right.$ flow rate $=12 \mathrm{~mL}$ $\min ^{-1}$, reaction liquid flow rate $=0.9 \mathrm{~mL} \mathrm{~min}^{-1}$ ) are shown in Fig. 3. An average conversion of $93 \%$ with a $62 \%$ selectivity towards styrene were obtained for Pd/PCFs. Compared to Pd/ PCFs catalysts, commercial Pd/C suffered from the over hydrogenation of styrene to ethylbenzene during selective liquidphase hydrogenation under the same reaction conditions; moreover, no selectivity was achieved. The conventional Lindlar catalyst showed a conversion of $51 \%$ and a $75 \%$ selectivity to styrene with the same content of Pd. Thus, the Pd/PCFs catalysts showed the better catalytic performance at the same Pd loading in phenylacetylene hydrogenation. Fig. 3 shows that after a $2 \mathrm{~h}$ reaction, no obvious change of activity and selectivity was 

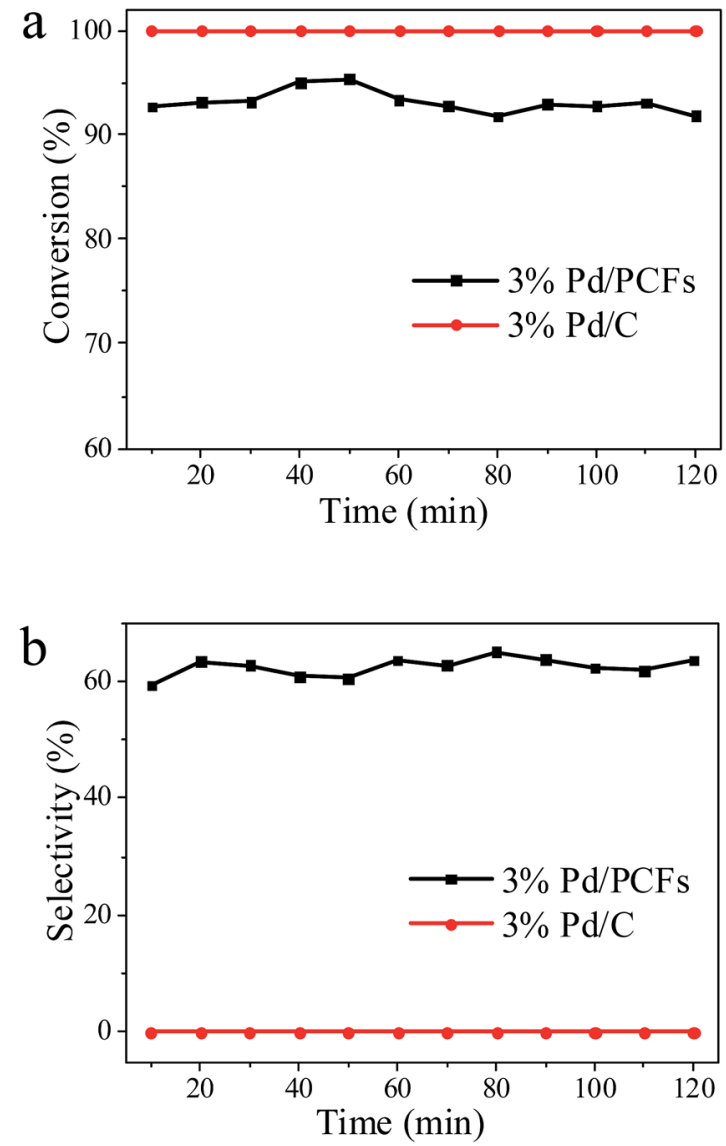

Fig. 3 The catalytic performance of $P d / P C F s$ and $P d / C$ in selective phenylacetylene hydrogenation.

observed for Pd/PCFs and Pd/C. To further evaluate the stability of the Pd/PCFs catalysts, as shown in Fig. S4, $\dagger$ a longer catalytic experiment for $10 \mathrm{~h}$ was performed. All these results demonstrate that the Pd/PCFs catalysts are relatively stable during the process of selective phenylacetylene hydrogenation.

X-ray diffraction (XRD) analyses of Pd/PCFs and Pd/C were carried out to obtain information on the crystallographic structure of these palladium nanoparticles. Fig. 4(a) shows the XRD patterns of both fresh Pd/PCFs and used Pd/PCFs catalysts after two hours reaction. The broad peaks at $\sim 25^{\circ}$ correspond to the (002) planes of low-graphitized carbonaceous structure can be observed, indicating that the porous carbon materials are disordered or amorphous. ${ }^{21}$ Sharp well-defined diffraction peaks were also observed at $2 \theta=40,46,68$, and $82^{\circ}$, attributed to the (111), (200), (220), and (311) planes of the face-centred cubic (fcc) crystal structure of palladium, respectively. ${ }^{23}$

The average size of palladium nanoparticles $(d)$ was estimated using the Scherrer's equation (eqn (1)) for the (111) peak at $2 \theta=40^{\circ}$ after background subtraction:

$$
d=k \lambda /(\beta \cos \theta)
$$

where $k$ is a coefficient, generally taken as $0.9, \lambda$ is wavelength of X-ray radiation $(1.5418 \AA), \beta$ is the full width at half maximum (FWHM) measured in radians, and $\theta$ is the angle measured for
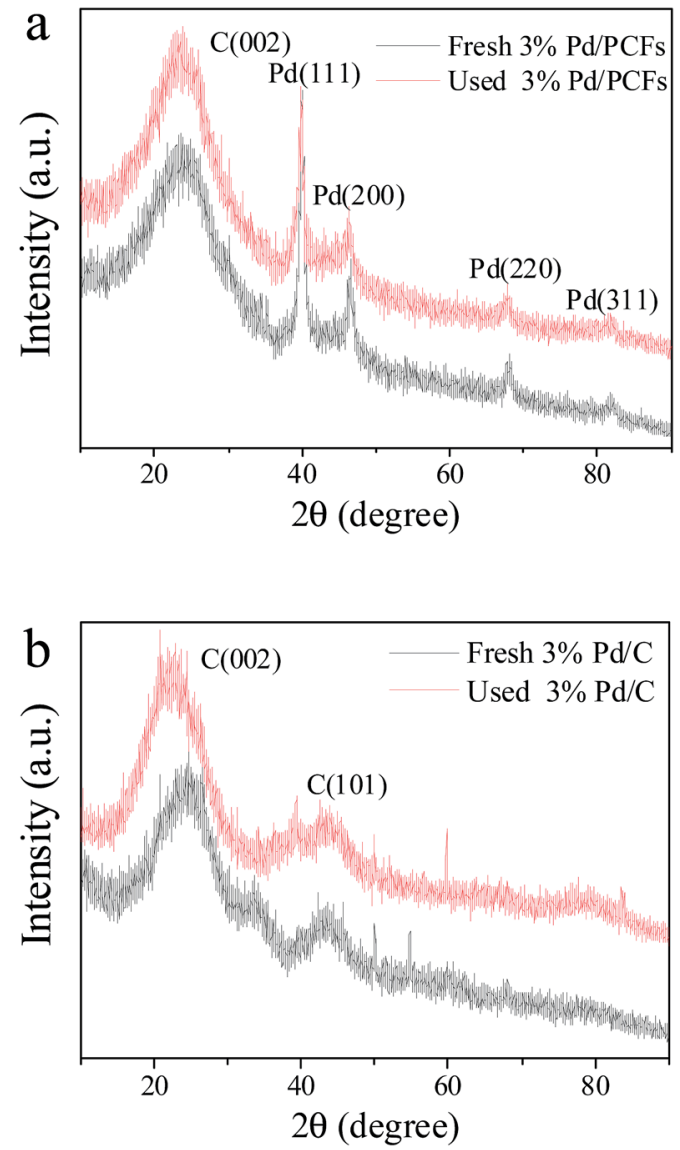

Fig. 4 XRD patterns of (a) Pd/PCFs before and after the $2 \mathrm{~h}$ reaction, (b) $\mathrm{Pd} / \mathrm{C}$ catalysts before and after the reaction.

the position of palladium peaks. The average palladium nanoparticle diameter calculated from the FWHM of the Pd (111) peak for the fresh Pd/PCFs catalyst is $15.9 \mathrm{~nm}$, equalling $14.6 \mathrm{~nm}$ for the used catalyst. The XRD pattern of Pd/C is shown in Fig. 4(b); in addition to the strong (002) peak at $\sim 25^{\circ}$, the pattern also showed peaks at $45^{\circ}$, ascribed to the (101) plane of graphite. This confirmed that the structure of the $\mathrm{Pd} / \mathrm{C}$ catalyst is intermediate between that of the disordered amorphous carbon phase and the highly ordered graphitic phase. ${ }^{23}$ However, the palladium nanoparticles supported on the carbon were too small to be detected by XRD, resulting in no evident diffraction peaks of palladium.

Raman spectroscopy is the most efficient way for providing quick and easy structural and qualitative characterization of carbon materials. Fig. 5 shows the Raman spectra of the fresh and used catalysts samples, demonstrating the disorder and defects of the carbon structure as well as the presence of amorphous carbon. The qualitative analysis of carbon nanostructures, based on the intensity ratio of the D band and $\mathrm{G}$ band $\left(I_{\mathrm{D}} / I_{\mathrm{G}}\right)$, reveals the in-plane crystallite dimensions and the amount of in-plane and edge defects in the above materials. The $I_{\mathrm{D}} / I_{\mathrm{G}}$ ratios of fresh PCFs, fresh Pd/PCFs and used Pd/PCFs are $0.90,0.92$ and 0.93 respectively. The similar peak positions and $I_{\mathrm{D}} / I_{\mathrm{G}}$ values observed for PCFs $(0.92-0.93)$ imply that these samples possess similar degrees of graphitization, while the $I_{\mathrm{D}} /$ $I_{\mathrm{G}}$ ratios of both fresh and used Pd/C equal 1.22. 


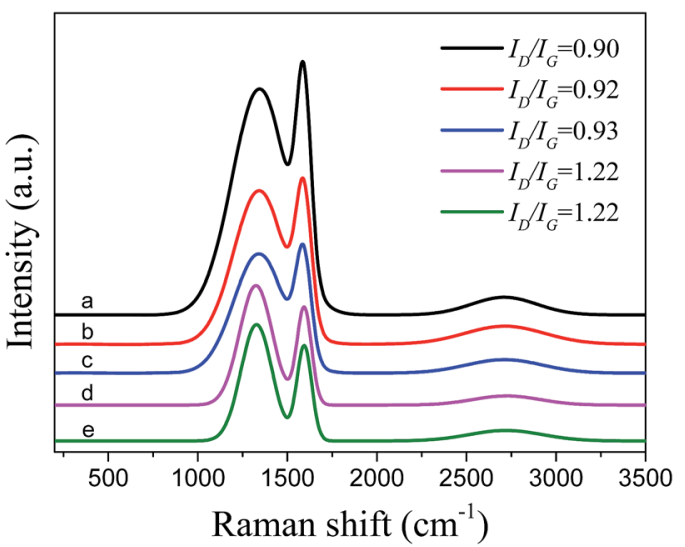

Fig. 5 Raman spectra of (a) fresh PCFs, (b) fresh Pd/PCFs catalysts, (c) used Pd/PCFs catalysts, (d) fresh $\mathrm{Pd} / \mathrm{C}$ catalysts, (e) used $\mathrm{Pd} / \mathrm{C}$ catalysts.

Fig. 6(a) and (b) shows the TEM images of fresh and used Pd/ PCFs respectively, with no obvious structural difference observed between them. The Pd/PCFs catalysts after hydrogenation did not have significant changes in size of palladium nanoparticles and maintaining a good distribution. Fresh Pd/C catalysts exhibited highly dispersed palladium nanoparticles on the carbon surface with an average diameter of $2-3 \mathrm{~nm}$, as shown in Fig. 6(c). However, used Pd/C catalysts after hydrogenation featured palladium nanoparticles with a larger average size, possibly due to the accumulated carbonaceous deposition and leaching of the Pd/C catalysts, as shown in Fig. 6(d).

To clarify the chemical state of palladium nanoparticles anchored on the catalyst samples, we carried out X-ray photoelectron spectroscopy (XPS) measurements to characterize the surface and near-surface properties of both fresh and used catalysts. Fig. 7(a) shows the fitted Pd 3d core-level XPS spectra of fresh $\mathrm{Pd} / \mathrm{PCFs}$, with the $\operatorname{Pd}(0) 3 \mathrm{~d}_{5 / 2}$ core electron binding energy equalling $335.5 \mathrm{eV}$. This binding energy value is in good agreement with that reported XPS data for monometallic

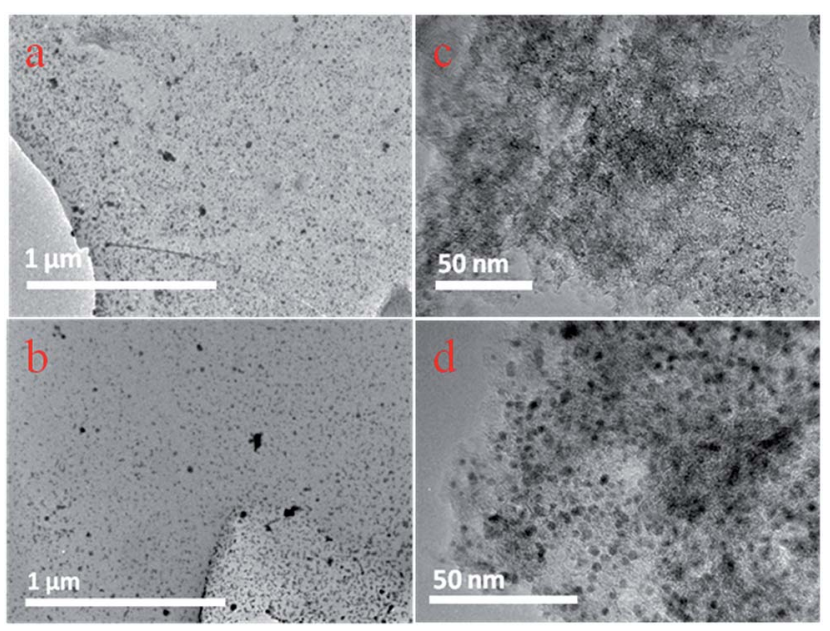

Fig. 6 (a) TEM images of the fresh Pd/PCFs catalysts. (b) TEM images of the used Pd/PCFs catalysts. (c) TEM images of the fresh Pd/C catalysts. (d) TEM images of the used Pd/C catalysts. palladium nanoparticles. Compared to the spectra of fresh $\mathrm{Pd} /$ PCFs, the $\operatorname{Pd}(0) 3 d_{5 / 2}$ binding energy of fresh Pd/C in Fig. 7 (b) is clearly shifted to $337.3 \mathrm{eV}$. As the size of the nanoparticles decreases, the Pd $3 \mathrm{~d}$ peak undergoes a positive binding energy shift. Comparison of the spectra of reacted Pd/PCFs in Fig. 7(c) with that of fresh Pd/PCFs in Fig. 7(a) clearly indicates that the interfacial interactions between $\operatorname{Pd}(0)$ and PCFs are relatively stable during catalysis. However, the spectra of fresh $\mathrm{Pd} / \mathrm{C}$ in Fig. 7 (b) and used Pd/C in Fig. 7 (d) show a clear $\operatorname{Pd}(0) 3 d_{5 / 2}$ negative binding energy shift for the used $\mathrm{Pd} / \mathrm{C}$ catalysts due to the size increase of the nanoparticles, which can affect the strength of the interaction between the reactants and the palladium surface. Considering metallic $\mathrm{Pd}(0)$ as the only active phase, the binding energy shift is likely due to the changed electronic properties of the active charcoal and the hydrocarbon deposits on the palladium surface formed because of its high activity. The carbon deposits are confirmed to exert an undesirable effect on the selectivity of alkyne hydrogenation. ${ }^{13,24}$ In the case of $\mathrm{Pd} / \mathrm{C}$, the Pd 3d profiles were clearly affected by the reaction, suggesting the occurrence of dynamic changes on the $\mathrm{Pd}$ surfaces of $\mathrm{Pd} / \mathrm{C}$ during the catalytic phenylacetylene hydrogenation, while the relatively stable Pd surface of Pd/PCFs was preserved under the same reaction conditions.

$\mathrm{H}_{2}$ temperature programmed reduction (TPR) was performed to provide necessary information about the nature of Pd species in various supported Pd catalysts. The TPR profiles of the Pd/PCFs and Pd/C samples are shown in Fig. 8. The two profiles show a negative $\left(\mathrm{H}_{2}\right.$ desorption) peak at about $70{ }^{\circ} \mathrm{C}$; this is due to the decomposition of Pd hydride, which is typical for palladium metals..$^{25}$ The Pd/PCFs catalysts exhibited two positive reduction peaks at $356{ }^{\circ} \mathrm{C}$ and $436{ }^{\circ} \mathrm{C}$, which could be attributed to the reduction of Pd species. ${ }^{26,27}$ The positive peaks corresponding to the hydrogen consumption together elution of carbonaceous deposits were observed both in Pd/PCFs $\left(568^{\circ} \mathrm{C}\right)$ and $\mathrm{Pd} / \mathrm{C}$ samples $\left(610^{\circ} \mathrm{C}\right){ }^{28}$ The Pd particles size measured by $\mathrm{H}_{2}$ pulse chemisorption for the Pd/PCFs catalysts is $3.9 \mathrm{~nm}$, which is bigger than that for $\mathrm{Pd} / \mathrm{C}(3.5 \mathrm{~nm})$. And Pd metal surface area is $3.8 \mathrm{~m}^{2} \mathrm{~g}^{-1}$ sample for Pd/PCFs and $4.3 \mathrm{~m}^{2} \mathrm{~g}^{-1}$ sample for $\mathrm{Pd} / \mathrm{C}$.

The key characteristics of a support, critical for catalyst performance can be divided in bulk and surface, chemical (composition and surface chemistry), structural (particle size and shape), and stability under reaction conditions. ${ }^{2}$ In this work, we observed higher selectivity with improved stability for Pd/PCFs in the liquid-phase phenylacetylene hydrogenation comparing to commercial Pd/C. For Pd/PCFs catalysts, the supporting porous carbon materials with unique surface properties and morphology maybe the most important factor determining the higher selectivity to styrene. The structural properties of the PCFs support in terms of porosity, and crystal phase may impact the diffusion and adsorption modes of phenylacetylene, modifying the catalytic performance. The increase in styrene selectivity can be regarded as the consequence of increased diffusion resistance affecting the surface fugacity of phenylacetylene inside the pores, causing the stronger alkane adsorption while preventing alkene readsorption; hence disabling consecutive hydrogen addition. ${ }^{29}$ 

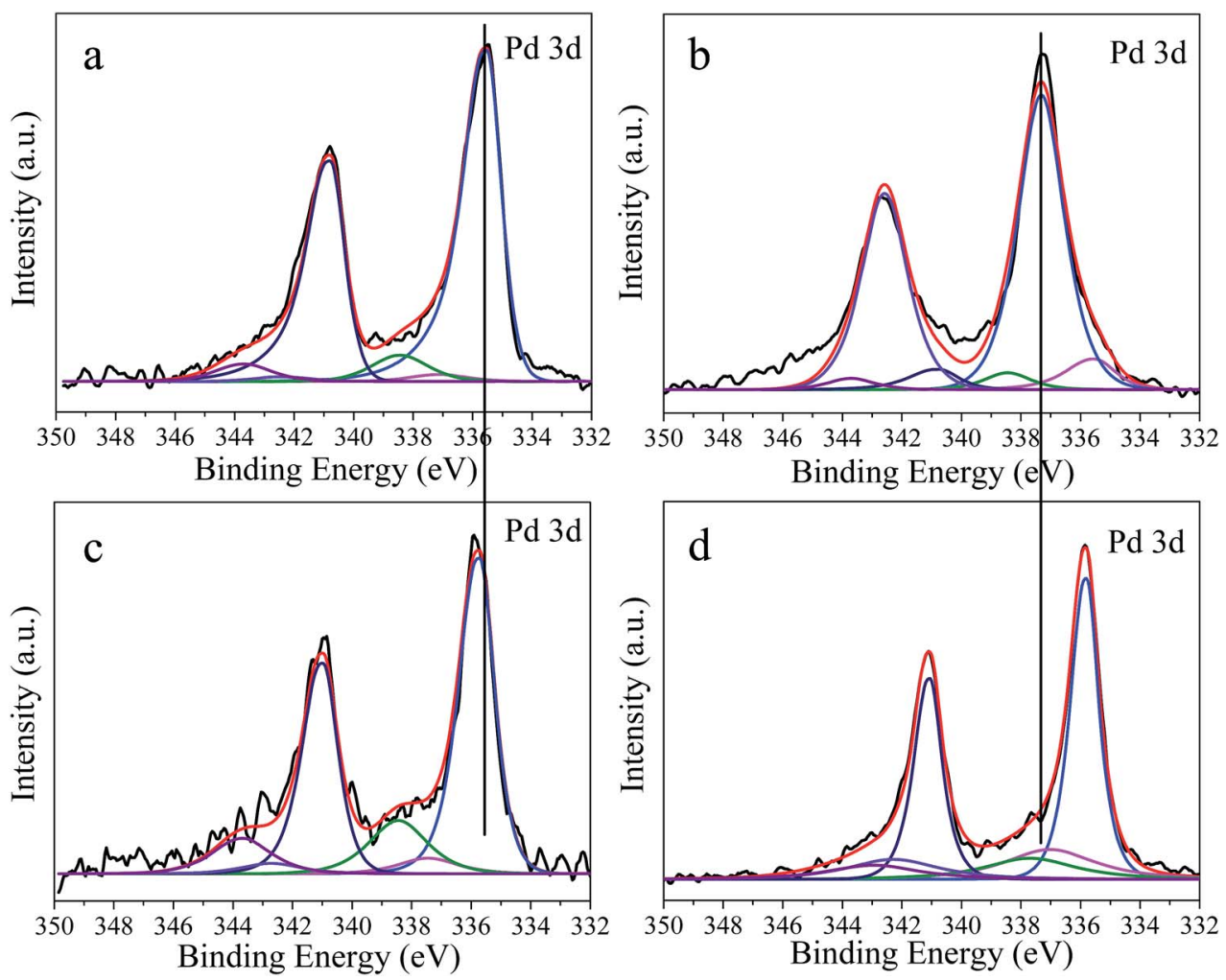

Fig. 7 Pd 3d XPS spectra for: (a) fresh Pd/PCFs catalyst, (b) fresh Pd/C catalyst, (c) used Pd/PCFs catalyst, (d) used Pd/C catalyst.

In general, the catalytic performance of the selective alkyne hydrogenation can be controlled by contributions due to the particle size, shape, and electronic properties of the metal phase. These features, in turn, can be affected by interactions with the support. The differences of the two studied catalysts in terms of activity and selectivity are believed to be caused by electronic and geometric effects. Some of the earlier results indicate that catalysts with low dispersion (higher particle size) ensure better selectivities for alkene formation. ${ }^{30-33} \mathrm{The} \mathrm{Pd} /$ PCFs catalysts with larger particles mainly possess large crystal planes with atoms having high coordination number (terrace atoms), whereas $\mathrm{Pd} / \mathrm{C}$ catalysts with small particles feature atoms with low coordination numbers (edge and corner

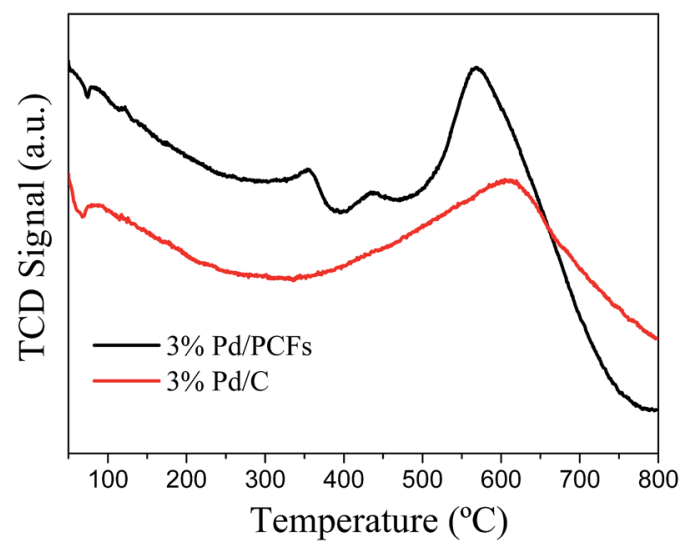

Fig. $8 \mathrm{H}_{2}$-TPR profiles of Pd/PCFs and Pd/C catalysts. atoms). ${ }^{25}$ The metal electron density is suggested to govern catalyst activity and affect the formation of surface carbonaceous deposits, thereby influencing selectivity, indicating that the metal-support interactions are stronger in $\mathrm{Pd} / \mathrm{C}$ than in $\mathrm{Pd} /$ PCFs. Thus the XPS spectra of used Pd/C catalysts undergoes a clear $\operatorname{Pd}(0) 3 d_{5 / 2}$ negative binding energy shift because of the size increase of the palladium nanoparticles. The strong metalsupport interactions (SMSI) in $\mathrm{Pd} / \mathrm{C}$ were assigned to the migration of support species onto the palladium nanoparticles, decreasing the accessible surface of palladium nanoparticles by encapsulation. ${ }^{34}$ It can be emphasized that a moderate contact of the Pd surface with the support greatly enhances the styrene selectivity and hydrogenation activity, decreasing for larger Pd particles. This means that the nature and strength of the moderate interactions of Pd nanoparticles with the PCFs support can induce increased metal particle stabilization and avoid undesirable effects such as metal leaching caused by the formation of carbonaceous deposits during the samples preparation and under reaction conditions.

\section{Conclusions}

In this study, palladium nanoparticles were supported on 3D porous carbon frameworks (Pd/PCFs) and used in the selective hydrogenation of phenylacetylene in a continuous-flow reactor under low temperatures. Commercially available catalysts featuring palladium on charcoal ( $3 \mathrm{wt} \% \mathrm{Pd} / \mathrm{C})$ were tested for comparison. The prepared Pd/PCFs catalysts with mean particle diameters of $3-16 \mathrm{~nm}$, achieved a $62 \%$ selectivity towards 
styrene with a $93 \%$ conversion under very mild conditions $\left(20^{\circ} \mathrm{C}, 3 \mathrm{bar}\right.$, hydrogen flow rate of $12 \mathrm{~mL} \mathrm{~min}^{-1}$, reaction liquid

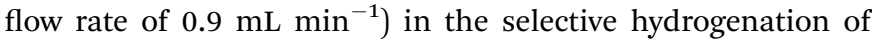
phenylacetylene. The supporting porous carbon materials exhibit coral-like morphology with unique surface properties and hierarchical pore structure are likely to be the most important factor determining the high styrene selectivity. For the Pd/PCFs catalysts, a moderate contact of the Pd surface with the support greatly enhances styrene selectivity and achieves good phenylacetylene conversion. The XPS spectra of $\mathrm{Pd} / \mathrm{C}$ catalysts after hydrogenation undergoes a clear $\operatorname{Pd}(0) 3 d_{5 / 2}$ negative binding energy shift because of the size increase of the palladium nanoparticles, while no significant differences were observed between the fresh and used Pd/PCFs catalysts. It can be emphasized that the nature and strength of the moderate interactions of Pd nanoparticles with the PCFs support can result in increased metal particle stabilization and avoid undesirable effects such as metal leaching caused by the formation of carbonaceous deposits during the samples preparation and under reaction conditions.

\section{Acknowledgements}

This work is supported by the National Natural Science Foundation of China (21403137).

\section{Notes and references}

1 M. Zhang, Y. Yang, C. Li, Q. Liu, C. C. T. Williams and C. Liang, Catal. Sci. Technol., 2014, 4, 329-332.

2 M. Crespo-Quesada, F. Cárdenas-Lizana, A. L. Dessimoz and L. Kiwi-Minsker, ACS Catal., 2012, 2, 1773-1786.

3 S. A. Nikolaev and V. V. Smirnov, Catal. Today, 2009, 147, S336-S341.

4 D. Teschner, Z. Révay, J. Borsodi, M. Hävecker, A. KnopGericke, R. Schlögl, D. Milroy, S. D. Jackson, D. Torres and P. Sautet, Angew. Chem., Int. Ed., 2008, 47, 9474-9478.

5 S. Domínguez-Domínguez, Á. Berenguer-Murcia, D. CazorlaAmorós and Á. Linares-Solano, J. Catal., 2006, 243, 74-81.

6 S. A. Nikolaev, N. A. Permyakov, V. V. Smirnov, A. Y. Vasil'kov and S. N. Lanin, Kinet. Catal., 2010, 51, 288-292.

7 S. Domínguez-Domínguez, Á. Berenguer-Murcia, B. K. Pradhan, Á. Linares-Solano and D. Cazorla-Amorós, $J$. Phys. Chem. C, 2008, 112, 3827-3834.

8 B. A. Wilhite, M. J. McCready and A. Varma, Ind. Eng. Chem. Res., 2002, 41, 3345-3350.

9 L. Shao, X. Huang, D. Teschner and W. Zhang, ACS Catal., 2014, 4, 2369-2373.

10 R. D. Adams, B. Captain and L. Zhu, J. Organomet. Chem., 2006, 691, 3122-3128.

11 E. Leitmannová, J. Svoboda, J. Sedláček, J. Vohlídal, P. Kačer and L. Červený, Appl. Catal., A, 2010, 372, 34-39.
12 W. Donphai, T. Kamegawa, M. Chareonpanich and H. Yamashita, Ind. Eng. Chem. Res., 2014, 53, 10105-10111.

13 L. Shao, B. Zhang, W. Zhang, D. Teschner, F. Girgsdies, P. Schlögl and D. S. Su, Chem.-Eur. J., 2012, 18, 14962-14966.

14 N. J. Divins, I. Angurell, C. Escudero, V. Pérez-Dieste and J. Llorca, Science, 2014, 346, 620-623.

15 M. M. Titirici, R. J. White, N. Brun, V. L. Budarin, D. S. Su, F. del Monte, J. H. Clark and M. J. MacLachlan, Chem. Soc. Rev., 2015, 44, 250-290.

16 L. Dai, D. W. Chang, J. B. Baek and W. Lu, Small, 2012, 8, 1130-1136.

17 W. Tian, H. Zhang, X. Duan, H. Sun, M. O. Tade, H. M. Ang and S. Wang, ACS Appl. Mater. Interfaces, 2016, 8, 7184-7193.

18 W. Gao, X. Feng, T. Zhang, H. Huang, J. Li and W. Song, ACS Appl. Mater. Interfaces, 2014, 6, 19109-19117.

19 J. Xu, M. Wang, N. P. Wickramaratne, M. Jaroniec, S. Dou and L. Dai, Adv. Mater., 2015, 27, 2042-2048.

20 H. Hou, C. E. Banks, M. Jing, Y. Zhang and X. Ji, Adv. Mater., 2015, 27, 7861-7866.

21 G. Yang, H. Han, T. Li and C. Du, Carbon, 2012, 50, 37533765.

22 T. Chen, Y. Liu, L. Pan, T. Lu, Y. Yao, Z. Sun, D. H. C. Chua and Q. Chen, J. Mater. Chem. A, 2014, 2, 4117-4121.

23 S. Shang, X. Yang and X. M. Tao, Polymer, 2009, 50, 28152818.

24 D. Teschner, J. Borsodi, A. Wootsch, Z. Révay, M. Hävecker, A. Knop-Gericke, S. D. Jackson and R. Schlögl, Science, 2008, $320,86$.

25 A. Sarkany, Z. Zsoldos, G. Stefler, J. Hightower and L. Guczi, J. Catal., 1995, 157, 179-189.

26 J. Zheng, M. Guo and C. Song, Fuel Process. Technol., 2008, 89, 467-474.

27 N. S. Babu, N. Lingaiah, R. Gopinath, P. S. S. Reddy and P. S. S. Prasad, J. Phys. Chem. C, 2007, 111, 6447-6453.

28 J. K. Murthy, S. C. Shekar, A. H. Padmasri, A. Venugopal, V. S. Kumar, B. M. Nagaraja, V. Shashikala, B. D. Raju, P. K. Rao and K. S. R. Rao, Catal. Commun., 2004, 5, 161-167.

29 A. Sarkany, A. Sárkány and M. Varga, J. Mol. Catal. A: Chem., 2001, 173, 185-221.

30 S. Hub, L. Hilaire and R. Touroude, Appl. Catal., 1988, 36, 307-322.

31 T. Kitamura, M. Sugeta and G. Sakata, Stud. Surf. Sci. Catal., 1999, 121, 427-430.

32 D. Duca, L. F. Liotta and G. Deganello, Catal. Today, 1995, 24, 15-21.

33 D. Ducaa, L. F. Liottaa and G. Deganelloa, J. Catal., 1995, 154, 69-79.

34 L. Zhang, H. Liu, X. Huang, X. Sun, Z. Jiang, R. Schlögl and D. Su, Angew. Chem., Int. Ed., 2015, 54, 15823-15826. 